OPEN ACCESS

Edited by:

Bela Volgyi,

University of Pécs, Hungary

Reviewed by:

Ulrike Janssen-Bienhold, University of Oldenburg, Germany

Sangsu Bang,

Duke University, United States

*Correspondence:

Monika Lakk

mlakk@gamma.ttk.pte.hu

David Križaj

david.krizaj@hsc.utah.edu

Received: 02 July 2018 Accepted: 20 September 2018 Published: 16 October 2018

Citation:

Lakk M, Young D, Baumann JM, Jo AO, Hu H and Križaj D (2018) Polymodal TRPV1 and TRPV4 Sensors Colocalize but Do Not Functionally Interact in a Subpopulation of Mouse Retinal Ganglion Cells.

Front. Cell. Neurosci. 12:353. doi: 10.3389/fncel.2018.00353

\section{Polymodal TRPV1 and TRPV4 Sensors Colocalize but Do Not Functionally Interact in a Subpopulation of Mouse Retinal Ganglion Cells}

\author{
Monika Lakk ${ }^{*}$, Derek Young ${ }^{1}$, Jackson M. Baumannn ${ }^{1,2}$, Andrew O. Jo ${ }^{1}$, Hongzhen Hu \\ and David Križaj ${ }^{1,2,4 *}$
}

\begin{abstract}
${ }^{1}$ Department of Ophthalmology and Visual Sciences, University of Utah, Salt Lake City, UT, United States, ${ }^{2}$ Department of Bioengineering, University of Utah, Salt Lake City, UT, United States, ${ }^{3}$ Department of Anesthesiology, Washington University School of Medicine, St. Louis, MO, United States, ${ }^{4}$ Department of Neurobiology and Anatomy, University of Utah, Salt Lake City, UT, United States
\end{abstract}

Retinal ganglion cells (RGCs) are projection neurons that transmit the visual signal from the retina to the brain. Their excitability and survival can be strongly influenced by mechanical stressors, temperature, lipid metabolites, and inflammatory mediators but the transduction mechanisms for these non-synaptic sensory inputs are not well characterized. Here, we investigate the distribution, functional expression, and localization of two polymodal transducers of mechanical, lipid, and inflammatory signals, TRPV1 and TRPV4 cation channels, in mouse RGCs. The most abundant vanilloid mRNA species was Trpv4, followed by Trpv2 and residual expression of Trpv3 and Trpv1. Immunohistochemical and functional analyses showed that TRPV1 and TRPV4 channels are expressed as separate molecular entities, with TRPV1only ( 10\%), TRPV4-only ( 40\%), and TRPV1 + TRPV4 ( 10\%) expressing RGC subpopulations. The TRPV1 + TRPV4 cohort included SMI-32-immunopositive alpha RGCs, suggesting potential roles for polymodal signal transduction in modulation of fast visual signaling. Arguing against obligatory heteromerization, optical imaging showed that activation and desensitization of TRPV1 and TRPV4 responses evoked by capsaicin and GSK1016790A are independent of each other. Overall, these data predict that RGC subpopulations will be differentially sensitive to mechanical and inflammatory stressors.

Keywords: retina, calcium, TRPV1, TRPV4, endocannabinoids, glaucoma, RGC

\section{INTRODUCTION}

Vertebrate vision is based on separating photon input from background thermal energy and extraction of luminance, local contrast, color, orientation, direction of motion, and "looming" information from the visual scene (Lettvin et al., 1959). Feature extraction is conducted in parallel by over 40 types of retinal ganglion cells (RGCs), which project axons from the retina to a wide range of midbrain nuclei (Morin and Studholme, 2014; Baden et al., 2016). RGCs are typically categorized by their light response and serendipitous expression of molecular markers 
(Zeng and Sanes, 2017) but this ignores the possibility that RGC might also be classified based on their responsiveness to the local milieu, which continually bombards them with mechanical, cardiovascular and immune signals. We know that non-canonical non-synaptic sensory inputs can dramatically impact the function and survival of RGC subtypes (Muller et al., 2014; Duan et al., 2015; Križaj, 2016; Ou et al., 2016) yet the lack of knowledge about the transduction mechanisms that mediate them hampers physiological insight and treatment in diseases such as glaucoma, diabetic retinopathy, ischemia, and traumatic ocular injury.

Transient receptor potential (TRP) vanilloid channels are polymodal cation channels that function as molecular integrators of many types of sensory input (Clapham, 2003; Nilius and Szallasi, 2014). The 28 isoforms that constitute the TRP superfamily function as transducers of the ambient physicochemical and inflammatory environment due to their sensitivity for mechanical stressors (strain, pressure, shear flow, swelling), temperature, $\mathrm{pH}$, lipid, and inflammatory metabolites. Because the channels are permeable to $\mathrm{Ca}^{2+}$ and can be activated at resting membrane potentials, they are able to modulate neuronal physiology in the absence of synaptic activation (Bradshaw et al., 2013; Redmon et al., 2017). An archetypal example is the dorsal root ganglion (DRG), composed of sensory neuron populations that can be classified by the relative expression of TRPV1 nociceptors, TRPV4 osmosensors, TRPM8 innocuous pain sensors, TRPA1 cold pain sensors, TRPM2 redox sensors, with TRPC1, TRPC6, and TRPV2 channels adding additional layers of complexity (Sousa-Valente et al., 2014; Teichert et al., 2014). Within the vanilloid subfamily, TRPV1-4 (also known as thermoTRPs for their temperature sensitivity) are non-selective cation channels whereas TRPV5 and TRPV6 are predominantly permeable to $\mathrm{Ca}^{2+}$ and typically expressed in epithelial and bone cells (Clapham, 2003). The most studied vanilloid isoforms are TRPV1 and TRPV4, with $\sim 50 \%$ sequence homology and activation by distinct agonists, temperature ranges, mechanical, osmotic, and inflammatory stressors (Martins et al., 2014; Nilius and Szallasi, 2014). Gene association and clinical studies identified single-nucleotide polymorphisms in the coding/promoter regions of TRPV4 with mutations that cause debilitating sensory and motor neuropathies and musculoskeletal disorders (Nilius and Voets, 2013; Echaniz-Laguna et al., 2014). Inflammatory agents sensitize TRPV1/4 channels by mechanisms that are not fully defined whereas selective inhibition or deletion of TRPV1- and TRPV4expressing neurons produces burning, freezing, itch, mechanical pain, and thermosensory phenotypes together with loss of osmoregulation and hearing loss (Caterina et al., 1997; Tominaga et al., 1998; Liedtke and Friedman, 2003; Alessandri-Haber et al., 2004).

Vertebrate retinas express many - perhaps most - TRP isoforms (Gilliam and Wensel, 2011; Križaj, 2016) yet studies of TRP signaling are in their infancy and it is unknown whether different isoforms work together to transduce complementary features of the intra-retinal milieu. In contrast to the canonical TRPC1 isoform which is expressed in most retinal cells (Molnar et al., 2012, 2016), the most extensively studied isoform - TRPV1 - was localized to photoreceptors and subsets of RGCs, bipolar, and amacrine cells (Yazulla, 2008; Middleton and Protti, 2011; Ryskamp et al., 2014a; Jo et al., 2017). Its cognate, TRPV4, has been detected in RGCs, Müller glia, and endothelial cells (Ryskamp et al., 2011, 2014b; Jo et al., 2015; Phuong et al., 2017; Taylor et al., 2017) but, unlike TRPV1, appears to be absent from amacrine, bipolar, and photoreceptor cells (Yarishkin et al., 2018). The relative expression of vanilloid isoforms across RGCs is unknown, nor is it clear whether TRPV1 and TRPV4 colocalize and/or can interact. Because heteromultimerization could increase the cells' capacity to sense changes in ambient environment, we studied the relative expression levels of TRPV1 and TRPV4 channels, investigated their functional distribution and integration, and tested the influence of channel activation on cellular calcium homeostasis in mouse RGCs. We identified distinct RGC constellations that include TRPV4-, TRPV1-, and TRPV1 + TRPV4expressing populations in which TRPV1 and TRPV4 channels are activated independently. These data suggest that sensing of ambient information (temperature, mechanical stress, $\mathrm{pH}$, and endocannabinoids) across physiological and pathological ranges may be differentially distributed across RGC populations.

\section{MATERIALS AND METHODS}

\section{Ethical Approval and Animals}

Animal handling, anesthetic procedures, and experiments were performed in accordance with the NIH Guide for the Care and Use of Laboratory Animals and the ARVO Statement for the Use of Animals in Ophthalmic and Vision Research. The project was approved by the Institutional Animal Care and Use Committees at the University of Utah. We assessed retinal TRPV1 expression using a knock-in mouse in which Cre was inserted into Exon 15 of Trpv1 (TRPV1Cre; Jackson Laboratory 017769). This line was crossed to B6.Cg-Gt(ROSA)26Sortm9(CAGtdTomato)Hze/J (Ai9; 007909) in which the LoxP-STOP-LoxP TdTomato construct is knocked in at the Gt(ROSA)26Sor locus (Madison et al., 2010; Jo et al., 2017). Trpv4 ${ }^{-/-}$mice have an excised exon 12-encoding transmembrane pore domains 5 and 6 (Liedtke and Friedman, 2003). C57BL/6J (C57), bacterial artificial chromosome (BAC)-transgenic Tg(TRPV4EGFP)MT43Gsat mice (referred to as TRPV4 ${ }^{\mathrm{eGFP}}$ ), TRPV1 ${ }^{-/-}$, TRPV4-/-, TRPV1Cre:Ai3, and Trpv1Cre:Ai9 mice were maintained in a pathogen-free facility with a 12-h light/dark cycle and unrestrained access to food and water. Data were gathered from male and female mice with no noted gender differences.

\section{Reagents}

The TRPV4 agonist GSK1016790A (GSK101) and antagonist HC-067047 (HC-06) were purchased from Sigma. The TRPV1 agonist capsaicin (CAP; 8-methyl-N-vanillyl-6nonenamide) and the TRPV1 antagonist capsazepine (CPZ; $N$-[2-(4-Chlorophenyl)ethyl]-1,3,4,5-tetrahydro-7,8-dihydroxy$2 \mathrm{H}$-2-benzazepine-2-carbothioamide) and the endogenous agonist of $\mathrm{CB} 1$ receptors 2-arachidonoylglycerol (2-AG) 
TABLE 1 | Primer sequences used for PCR and semiquantitative real-time PCR analysis.

\begin{tabular}{|c|c|c|c|}
\hline Name & Forward primer & Reverse primer & Product size (bp) \\
\hline Trpv1 & AGGGTGGATGAGGTGAACTGGACT & GCTGGGTGCTATGCCTATCTCG & 199 \\
\hline Trpv2 & GTTGGCCTACGTCCTCCTCACCTA & TGCACCACCAGTAACCATTCTCC & 158 \\
\hline Trpv3 & CTCACСТTCGTССТССТССТСААС & CAGCCGGAAGTCCTCATCTGCTA & 201 \\
\hline Trpv4 & TCCTGAGGCCGAGAAGTACA & TCCCCCTCAAACAGATTGGC & 166 \\
\hline Gapdh & GGTTGTCTCCTGCGACTTCA & TAGGGCCTCTCTTCCTCAGT & 220 \\
\hline Actb & CCACCATGTACCCAGGCATT & AGGGTGTAAAACGCAGCTCA & 253 \\
\hline
\end{tabular}

were obtained from Cayman Chemicals. BDNF and CNTF used to culture RGCs were obtained from GenWay Biotech. Other salts and reagents were purchased from Sigma, VWR, Across Organics, or Thermo Fisher. GSK101 (1 mM), HC-06 (10 mM), CAP (10 mM), and CPZ (20 mM) stocks in DMSO were diluted in extracellular saline before use and placed into reservoirs connected to gravity-fed perfusion systems (Warner Instruments).

\section{Magnetic-Activated Cell Sorting (MACS)}

The retinas were incubated in an enzyme solution containing $16 \mathrm{U} / \mathrm{ml}$ papain (Worthington), $0.2 \mathrm{mg} / \mathrm{ml} \mathrm{L}$-cysteine (Sigma), and $50 \mathrm{U} / \mathrm{ml}$ DNase I recombinant (Roche) for $45 \mathrm{~min}$ at $37^{\circ} \mathrm{C}$ with gentle agitation and triturated with D-PBS solution containing $1.5 \mathrm{mg} / \mathrm{ml} \mathrm{BSA}, 1.5 \mathrm{mg} / \mathrm{ml}$ Trypsin inhibitor, $\mathrm{pH}$ : 7.4, to yield a single cell suspension that was passed through a $30 \mu \mathrm{m}$ pre-separation filter and centrifuged. The cell pellet was re-suspended and incubated in $0.5 \%$ BSA solution containing CD90.1 MicroBeads (1:10; Miltenyi Biotech) for $15 \mathrm{~min}$ at $4^{\circ} \mathrm{C}$. After additional washing and centrifugation, cells were separated using MACS LS columns and incubated in serum-free neurobasal medium (Gibco/ThermoFisher) with $1 \%$ penicillin/streptomycin (Sciencell), transferrin (0.1 $\mathrm{mg} / \mathrm{ml})$, putrescine $(16 \mathrm{ng} / \mathrm{ml})$, insulin $(5 \mu \mathrm{g} / \mathrm{ml}), 3,5,3$ triiodothyronine T3 (100 $\mathrm{nM})$, progesterone (20 nM), 2\% B27, N-acetyl cysteine $(5 \mathrm{ng} / \mathrm{ml})$, sodium pyruvate $(1 \mathrm{mM})$, L-glutamine (2 $\mathrm{mM})$, brain-derived neurotrophic factor (BDNF, $50 \mathrm{ng} / \mathrm{ml}$ ), ciliary neurotrophic factor (CNTF, $10 \mathrm{ng} / \mathrm{ml}$ ), and forskolin $(5 \mu \mathrm{M})$. The growth medium was changed every $2-3$ days.

\section{Semiquantitative Real-Time PCR}

Total RNA was isolated using the Arcturus PicoPure RNA Isolation Kit (Applied Biosystems) as described (Phuong et al., 2017). One microgram of total RNA was used for reverse transcription. First-strand cDNA synthesis and PCR amplification of cDNA were performed using $\mathrm{qScript}^{\mathrm{TM}}$ XLT cDNA SuperMix cDNA synthesis kit (Quanta Biosciences). The PCR products were run on $2 \%$ agarose gels and visualized by ethidium bromide staining, along with 100-bp DNA ladder (ThermoFisher). SYBR Green-based real-time PCR was performed using Apex qPCR Master Mix (Genesee Scientific). The results were performed in triplicate of at least four separate experiments. The comparative $\mathrm{C}_{\mathrm{T}}$ method $\left(\Delta \Delta \mathrm{C}_{\mathrm{T}}\right)$ was used to measure relative gene expression where the fold enrichment was calculated as: $2^{-[\Delta \mathrm{CT}(\text { sample })-\Delta \mathrm{CT} \text { (calibrator) }]}$ after normalization.
To normalize fluorescence signals, GAPDH and $\beta$-actin were utilized as endogenous controls. The primer sequences and expected product sizes are given in Table $\mathbf{1}$.

\section{Retinal Dissociation and Optical Imaging}

The animals were euthanized by isoflurane inhalation. The retinas were isolated in ice-cold Leibovitz 15 (L15) medium containing $11 \mathrm{mg} / \mathrm{ml} \mathrm{L15}$ powder, with (in mM) 20 D-glucose, 10 Na-HEPES, 2 sodium pyruvate, 0.3 sodium ascorbate, and 1 glutathione. Incubation in L15 containing papain (7 U/ml; Worthington) digested the extracellular matrix, and was terminated by rinsing with cold L15 solution; $500 \mu \mathrm{m}$ pieces of retina were mechanically dissociated and cells were plated onto concanavalin A $(0.2-0.5 \mathrm{mg} / \mathrm{ml})$ coated coverslips. Calcium imaging followed established protocols (Ryskamp et al., 2011; Jo et al., 2016; Lakk et al., 2017), with the cells loaded with the Fura-2 AM (5-10 $\mu \mathrm{M}$, Life Technologies) indicator dye for 45$60 \mathrm{~min}$. Extracellular saline contained: (in $\mathrm{mM}$ ) $133 \mathrm{NaCl}, 10$ HEPES hemisodium salt, 10 glucose, $2.5 \mathrm{KCl}, 2 \mathrm{CaCl}_{2}, 1.5 \mathrm{MgCl}_{2}$, $1.25 \mathrm{NaH}_{2} \mathrm{PO}_{4}, 1$ pyruvic acid, 1 lactic acid, and 0.5 glutathione. Epifluorescence images were acquired using an inverted Nikon microscope with a 40x (1.3 NA oil) objective. Subsets of cells were stimulated with agonists and antagonists of TRPV1/4 channels. 340 and $380 \mathrm{~nm}$ excitation was delivered from an Xe lamp (Lambda DG-4, Sutter Instruments). Emissions were collected at $510 \mathrm{~nm}$ with 14-bit CoolSNAPHQ2 or Delta Evolve cameras and analyzed using NIS-Elements. $\Delta R / R$ (peak $F 340 / F 380$ ratio baseline/baseline) was used to quantify the amplitude of $\mathrm{Ca}^{2+}$ signals.

\section{Immunofluorescence}

The immunolabeling protocol for vertical sections followed the procedures described in Molnar et al. (2016) and Jo et al. (2017). The retinas were fixed for $1 \mathrm{~h}$ in $4 \%$ paraformaldehyde, rinsed with PBS, dehydrated, and embedded in OCT compound mounting medium (Electron Microscopy Sciences); $12 \mu \mathrm{m}$ thick cryosections were incubated in a blocking buffer (5\% FBS and $0.3 \%$ Triton X-100 in $1 \mathrm{X}$ PBS) for $20 \mathrm{~min}$. Primary antibodies (rabbit anti-TRPV4, 1:1000, LifeSpan Biosciences; rabbit antiRBPMS, 1:500, PhosphoSolutions; mouse anti-Thy1.1, Sigma, 1:500; mouse SMI-32, 1:100, Covance; mouse anti-GFP, 1:500, Santa Cruz) were diluted in the diluent (2\% BSA and $0.2 \%$ Triton X-100 in 1X PBS) and applied overnight at $4^{\circ} \mathrm{C}$, followed by incubation in fluorophore-conjugated secondary antibodies (1:500; goat anti-mouse AlexaFluor 405, 488, or 647, goat antirabbit AlexaFuor 488 or 594, Life Technologies) for $1 \mathrm{~h}$ at 
RT. Images were acquired on an Olympus CV1200 confocal microscope using 20x (NA water) and 40x (0.9 NA water) objectives.

\section{Statistical Analysis}

Data are presented as means \pm SEM. Statistical comparisons were made with one-way ANOVA test followed by post hoc Tukey's multiple comparison of means (Origin 8.0, Origin Lab Corporation). A difference of $P \leq 0.05$ (*) $^{*} P \leq 0.01$ $\left.\left.{ }^{* *}\right), P \leq 0.001{ }^{(* * *}\right)$, and $P \leq 0.0001^{(* * *)}$ ) were considered statistically significant.

\section{RESULTS}

\section{Mammalian RGCs Express Multiple Vanilloid TRP Isoforms}

Vanilloid TRP channels are osmo- and thermosensitive nonselective cation channels with critical functions in neuronal neural plasticity, synaptic transmission, synapse formation, neurogenesis, apoptosis, and survival (Sousa-Valente et al., 2014; Ramírez-Barrantes et al., 2016; White et al., 2016). The mouse retina expresses multiple members of the vanilloid subfamily (Gilliam and Wensel, 2011) but their relative expression in RGCs is not known. RNA profiling shows that mouse RGCs express all four thermo $\operatorname{Tr} p$ transcripts $(\operatorname{Tr} p v 1-4)$ (Figure 1A), with expression dominated by $\operatorname{Tr} p v 4$, followed by $\operatorname{Tr} p v 2$, $\operatorname{Trpv3}$, and Trpv1 mRNAs, respectively (Figure 1B). TRPV4 ${ }^{-/-}$ RGCs showed a trend toward Trpv1 upregulation but these changes were not significant (Figure 1C). Examination of mRNAs in TRPV4 ${ }^{-/}$RGCs showed little evidence of crossisoform plasticity apart from a (non-significant) trend toward Trpv1 (Figure 1C). We conclude that mouse RGCs as a group express all non-epithelial vanilloid $\operatorname{Trp}$ genes. Lack of compensatory upregulation in $\mathrm{KO}$ mice lacking the dominant TRPV4 channel might indicate absence of regulatory interaction at the transcriptional level, or an absence of obligatory heteromerization.

\section{Pharmacological Activation of TRPV1 and TRPV4 Channels Reveals Functional Overlap in a Subset of RGCs}

TRPV1 and TRPV4 channels have been implicated in optic nerve degeneration (Križaj et al., 2014; Sappington et al., 2015) and axonal neuropathies (Echaniz-Laguna et al., 2014), and shown to be sensitive to mechanical stressors (such as changes in cell volume and strain; Sudbury et al., 2010; Ryskamp et al., 2016). To categorize the relative fractions of TRPV1- and TRPV4expressing RGCs, we used microfluorimetry. Dissociated cells were identified by the size and morphology of the somata, and responsiveness to glutamate $(100 \mu \mathrm{M})$ and high $\mathrm{K}^{+}$ (35 mM; Ryskamp et al., 2011). After loading with the calcium indicator Fura-2-AM, cells were stimulated with pharmacological activators and inhibitors of TRPV1 and TRPV4 channels. The largest RGC cohort (35.08\%) showed intracellular $\mathrm{Ca}^{2+}\left(\left[\mathrm{Ca}^{2+}\right]_{\mathrm{i}}\right)$ increases in response to the TRPV4 agonist GSK101 (25 nM)
A

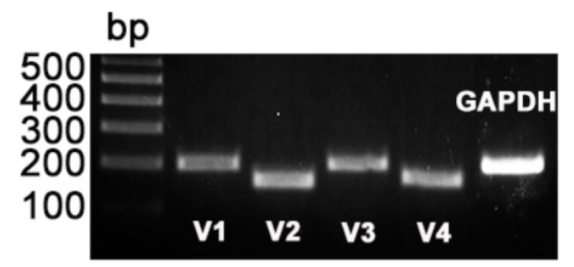

B

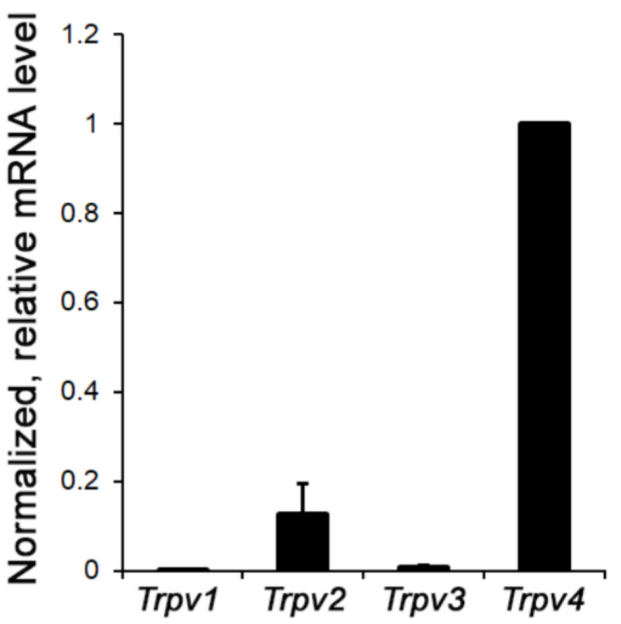

C

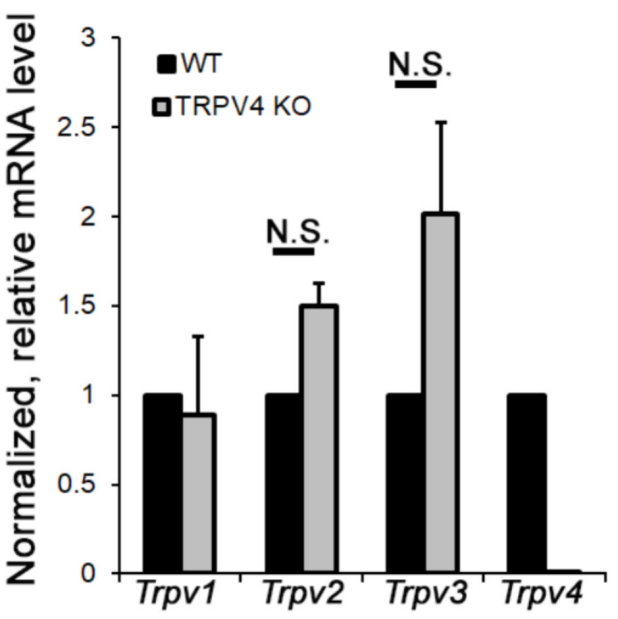

FIGURE 1 | Relative mRNA expression levels of vanilloid thermoTRP channels in primary mouse RGCs. (A) End point PCR. RGCs express all four thermo Trpv transcripts. Gapdh (glyceraldehyde 3-phosphate dehydrogenase) mRNA served as a loading control. (B) Semiquantitative RT-PCR. The relative abundance of thermo Trpv transcripts normalized with respect to Trpv4 content $(n=4)$. (C) Fold change in mRNA expression in TRPV4 ${ }^{-/}-$RGCs $(n=4)$ was calculated relative to expression in wild type cells.

and lack of sensitivity to the TRPV1 agonist CAP $(10 \mu \mathrm{M}$; Figures 2A,B). On average, in these cells, GSK101 evoked an increase in the $340 / 380$ ratio of $0.51 \pm 0.05(n=87 ; P<0.001)$. As shown previously (Ryskamp et al., 2011, 2014a), the responses to the TRPV4 agonist were characterized by a transient $\left[\mathrm{Ca}^{2+}\right]_{\mathrm{i}}$ 
A
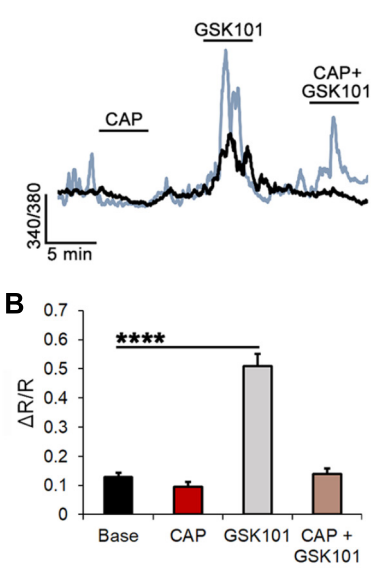

C
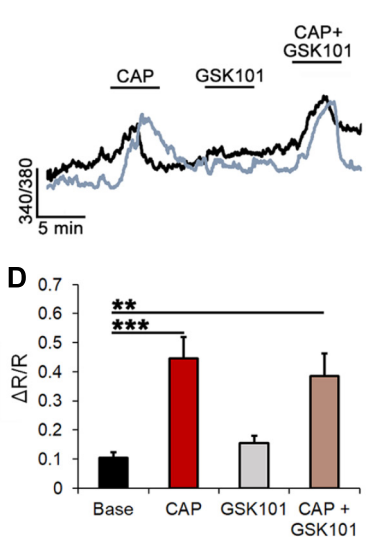

E
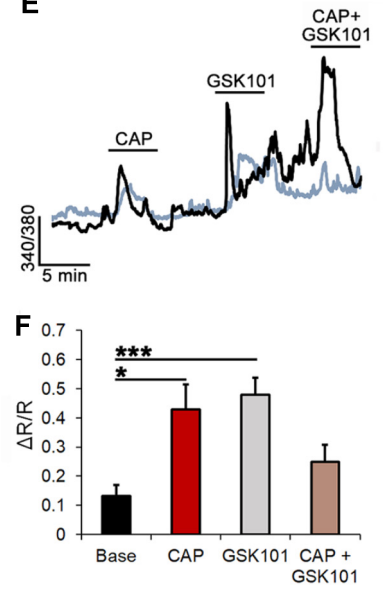

G

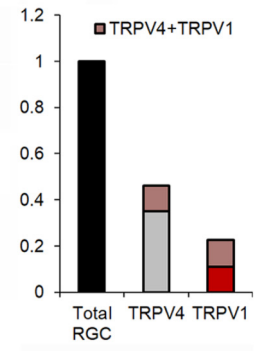

FIGURE 2 | TRPV1 and TRPV4 modulate $\mathrm{Ca}^{2+}$ homeostasis in subsets of RGCs. (A) Two simultaneously recorded RGCs (denoted by black and blue traces) respond to GSK101 with $\left[\mathrm{Ca}^{2+}\right]_{i}$ elevations but are insensitive to CAP. (B) Averaged data for the GSK101-responding CAP-insensitive pool of cells $(n=87$ ). (C) Representative traces of CAP responders that were insensitive to GSK101. (D) Averaged data for the CAP-responding GSK101-insensitive cohort ( $n=29)$. (E,F) Traces and averaged data from GSK101 + CAP responders $(n=27)$. (G) Summary of averaged data. $\sim 24 \%$ of the TRPV4-expressing RGCs responded to CAP, whereas $\sim 48 \%$ of TRPV1-expressing RGCs responded to GSK101. ${ }^{*} P \leq 0.05,{ }^{* *} P \leq 0.01,{ }^{* * *} P \leq 0.001,{ }^{* * * *} P \leq 0.0001$.

peak that inactivated in the continued presence of GSK101. Subsequent co-applications of the drug evinced lower-amplitude or missing $\mathrm{Ca}^{2+}$ responses due to tachyphylaxis (continued channel desensitization). Pretreatment with CAP did not affect the amplitude of GSK101-evoked $\left[\mathrm{Ca}^{2+}\right]_{\mathrm{i}}$ responses in this cohort, suggesting that tachyphylaxis is isoform-specific.

Another population, encompassing $11.69 \%$ of RGCs, responded to CAP administration with increased $\left[\mathrm{Ca}^{2+}\right]_{\mathrm{i}}$ with an average CAP-evoked ratio increase of $0.45 \pm 0.07(n=29$; $P<0.001$; Figures 2C,D). These cells were unresponsive to GSK101, and co-application of GSK101 and CAP yielded a ratio increase of $0.39 \pm 0.08$ that was not significantly different from the exposure to CAP alone. The third functional type (10.89\%) responded to both TRPV1 and TRPV4 agonists $(0.43 \pm 0.09$ and $0.48 \pm 0.06$ ratio increases, respectively; $n=27$; Figures 2E,F). A representative example of a cell classified into the third cohort is shown in Figure 3, with vertical lines in Figure 3A, corresponding to fluorescence images of free $\left[\mathrm{Ca}^{2+}\right]_{i}$ elevations in the RGC cytosol shown in Figure 3B. As expected (Ryskamp et al., 2011; Jo et al., 2017), the response to both agonists desensitized in the continued presence of the agonist (Figures 3Biv,viii). The dataset in Figure 2G shows that $\sim 46 \%$ of total glutamate responder RGCs express TRPV4, and $\sim 20 \%$ express TRPV1. Another way of parsing the data shows that $\sim 48 \%$ of TRPV 1 expressing RGCs $(22.6 \%$ of total glutamateresponding cells) functionally express TRPV4 channels whereas $\sim 24 \%$ of TRPV4-expressing cells express TRPV1 as well.

\section{TRPV4 Is Coexpressed With TRPV1 in a Subset of RGCs}

We next investigated whether the results from functional studies (Figures 2, 3) can be mirrored by proof-of-principle histochemical evidence. TRPV4 channels can be studied

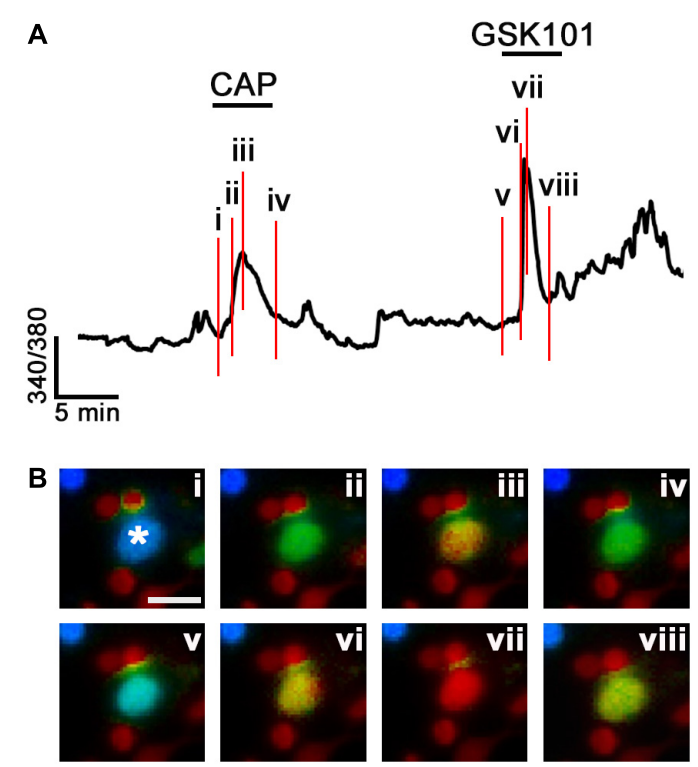

FIGURE 3 | Functional coexpression of TRPV1 and TRPV4 channels in a representative RGC (asterisk). (A) The time course of the calcium response in a C57 RGC sequentially stimulated with CAP and GSK101. The red vertical lines denote the time points shown in panel $\mathbf{B i}$-viii. (B) Ratio images from the RGC (asterisk) shown in A. Note that $\left[\mathrm{Ca}^{2+}\right]_{i}$ declines in the continued presence of both agonists. The small-diameter somata adjacent to the RGC are rod somata. Scale bar $=10 \mu \mathrm{m}$. 

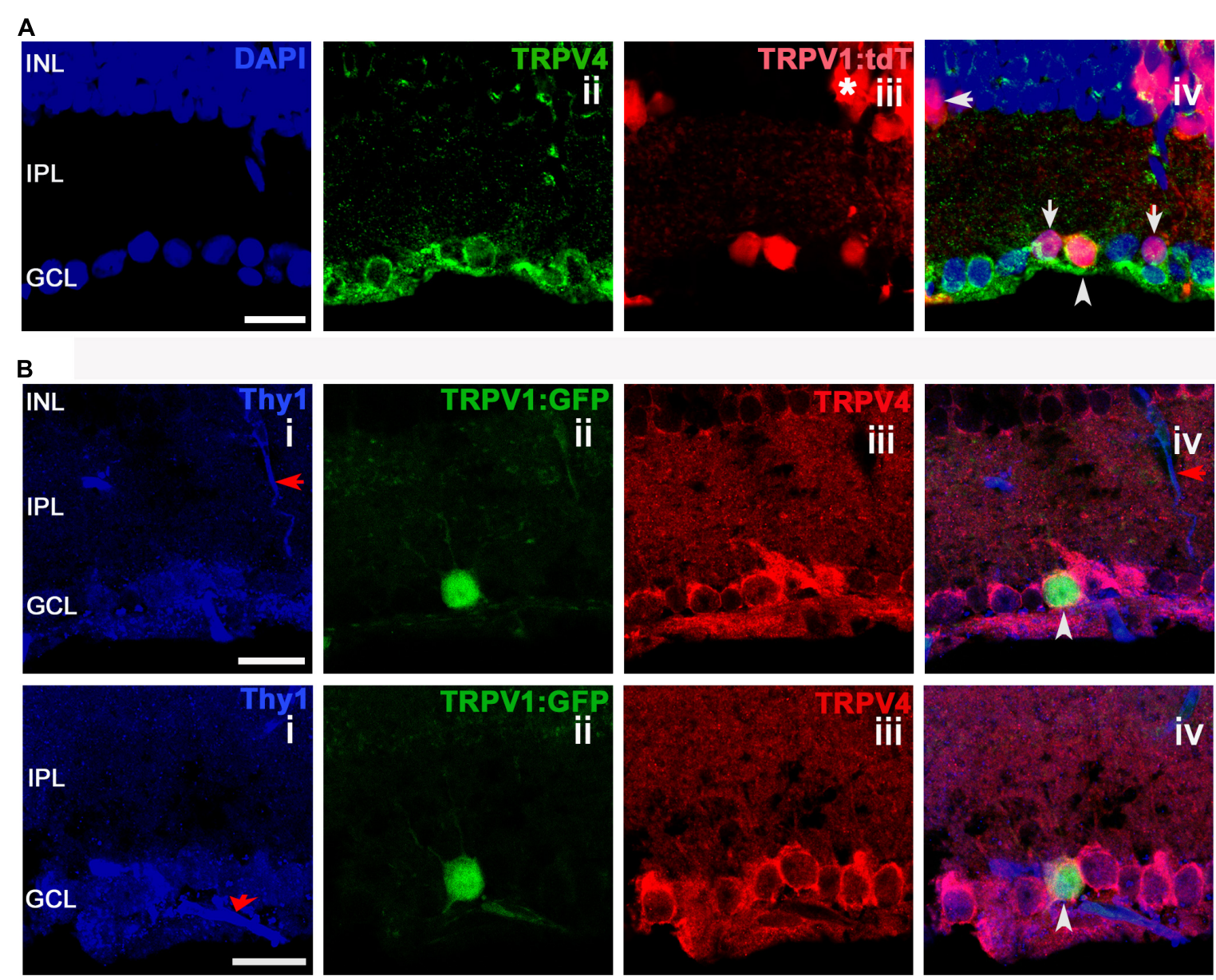

FIGURE 4 | TRPV1 expression in RGCs but not amacrine cells overlaps with TRPV4-ir. Confocal microscopy, vertical sections from the mouse retina. (A) TRPV1Cre/Ai9 retina labeled for DAPI, TRPV4, and TRPV1. TRPV1:tdTomato is expressed in cell somata localized in ganglion cell layer (GCL), inner nuclear layer (INL), and in a subset of putative Müller cells (asterisk). RGC that colocalizes TRPV1 and TRPV4 is marked by an arrowhead in panel iv. Arrows mark putative (small-diameter) amacrine cells in RGCL and IPL that are TRPV4- ${ }^{-}$. (B) TRPV1Cre/Ai3 section showing a TRPV1+ cell labeled by the GFP reporter. The cell was immunopositive for TRPV4 and Thy1. Red arrows donate blood vessels. Pictures were obtained from two optical sections with a thickness of $1 \mu \mathrm{m}$. Scale bars $=20 \mu \mathrm{m}$.

patterns of tdTomato and GFP reporters, respectively (Mishra and Hoon, 2010; Jo et al., 2017). Cells were evaluated in vertical sections from the central- to mid-peripheral retina in order to increase the likelihood of hitting on TRPV1-expressing RGCs (e.g., Jo et al., 2017).

We found that TRPV4 is localized to a substantial population of putative RGCs (identified by Thyl or RBPMS-ir). TRPV1 ${ }^{+}$ cells, identified by $\mathrm{tdT}^{+}$and $\mathrm{GFP}^{+}$fluorescence (Figure 4), typically colocalized with TRPV4-ir, with rare examples (arrow in Figure 4A) that were immunonegative for TRPV4. Two examples of TRPV ${ }^{\text {GFP }}$ cell that colocalized the RGC marker Thy1 (CD90) with TRPV4 are shown in Figure 4B (arrowheads). Although Thy1 labels a subset of displaced cholinergic syntaxin ${ }^{+}$cells in the RGC layer (Raymond et al., 2008), the presence of TRPV4 (which is absent from amacrines; Ryskamp et al., 2011) indicates that the labeled cell is a RGC.

We investigated whether TRPV1 and 4 channels might be expressed in SMI-32 cells, which label $\alpha$ RGCs, large-diameter monostratified cells that arborize in ON or OFF sublaminae of the inner plexiform layer (Coombs et al., 2006), play a role in contrast sensitivity and are sensitive to ocular hypertension (Della Santina et al., 2013; Schmidt et al., 2014; Ou et al., 2016). All TRPV1-expressing RGCL cells were immunopositive for SMI-32 and TRPV4. Figures 5A,B show a TRPV1-expressing $\left(\mathrm{RBPMS}^{+}\right)$ RGC that strongly expresses SMI-32. Another example, shown in Figures 5C,D, showcases a TRPV1-expressing $\alpha$ RGC that also expresses TRPV4 (arrowhead in Figure 5D), whereas a TRPV1-expressing putative amacrine cell (arrow in Figure 5C) was TRPV4 immunonegative. We conclude that most RBPMS ${ }^{+}$ TRPV ${ }^{+}$cells are SMI- $32^{+}$and can thus be classified as $\alpha$ RGCs. Of SMI-32 ${ }^{+}$cells, $35.9 \%$ were TRPV $1^{+}$. TRPV1 expression was detected in some Müller cells that were immunopositive for TRPV4 (asterisks in Figure 4A). These data suggest that RGCs sense their ambient environment through different combinations of sensory transducers, with TRPV4 channels as dominant nonepithelial vanilloid transducers. Moreover, Müller glia appear to 


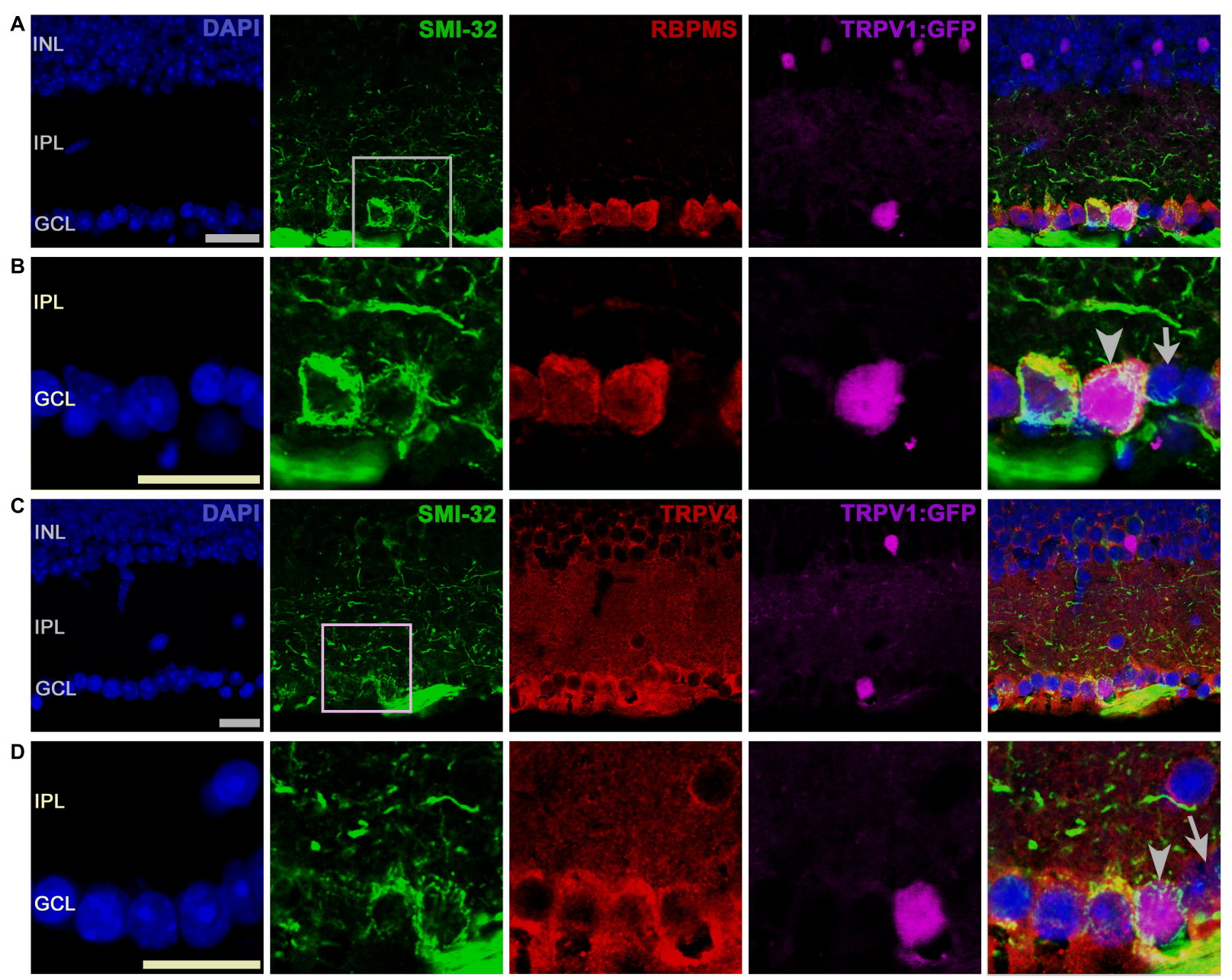

FIGURE 5 | SMI-32+ RGCs coexpress TRPV1 and TRPV4 signals. (A) A representative TRPV1-expressing RGC is labeled by the GFP reporter that was immunopositive for SMI-32 and RBPMS. (B) Inset from A. (C) TRPV1-expressing RGCL neuron is labeled by SMI-32 and TRPV4 (D, arrowhead) antibodies. The arrow denotes a TRPV4- and SMI-32-immunonegative putative amacrine cell in the proximal INL. Pictures were obtained from one optical section. Scale bars $=20 \mu \mathrm{m}$.

express both vanilloid isoforms, which is consistent with their function as regulators in the retinal microenvironment (Ryskamp et al., 2015).

\section{TRPV4 Signaling in TRPV1-Expressing RGCs Does Not Involve Subunit Heteromerization}

Vanilloid TRP channels preferentially assemble into homomeric channels (Hellwig et al., 2005); however, formation of macromolecular complexes between TRPV4 and TRPC1 (Ma et al., 2015), TRPP2 (Stewart et al., 2010), and TRPV1 (Sappington et al., 2015) has been reported for endothelial, kidney, and ganglion cells, respectively. We recently reported that pharmacological blockade of TRPV4 has no effect on TRPV1-mediated calcium signals (Jo et al., 2017). Here, we took advantage of transgenic mice to test whether heteromerization with TRPV1 is obligatory for TRPV4 functionality. To test TRPV1-V4 interactions, we assessed the responsiveness to CAP in RGCs expressing a fluorescent reporter (eGFP) under the control of the TRPV4 promoter $(\mathrm{Gu}$ et al., 2016). Recordings from CAP responding TRPV4 ${ }^{\mathrm{eGFP}+}$ RGCs (Figures 6Ai,ii) showed an absence of effect of the TRPV1 antagonist CPZ on baseline $\left[\mathrm{Ca}^{2+}\right]_{\mathrm{i}}$. The amplitude of GSK101-induced $\left[\mathrm{Ca}^{2+}\right]_{\mathrm{i}}$ elevations in the presence of $\mathrm{CPZ}$ was $0.66 \pm 0.12(n=12, P<0.001$; Figures 6A,B), not significantly different from GSK101 responses in WT cells $(0.51 \pm 0.05$; Figure 2D). These data indicate that TRPV1 in mouse RGCs is not required for TRPV4 function and vice versa, TRPV4-mediated responses are largely unaffected by TRPV1 knockdown.

\section{TRPV1 Channel Does Not Influence TRPV4 Functionality in Subset of RGCs}

Expression of cannabinoid receptors in most, if not all, mammalian retinal cells (Ryskamp et al., 2014b; Jo et al., 2017) 
A
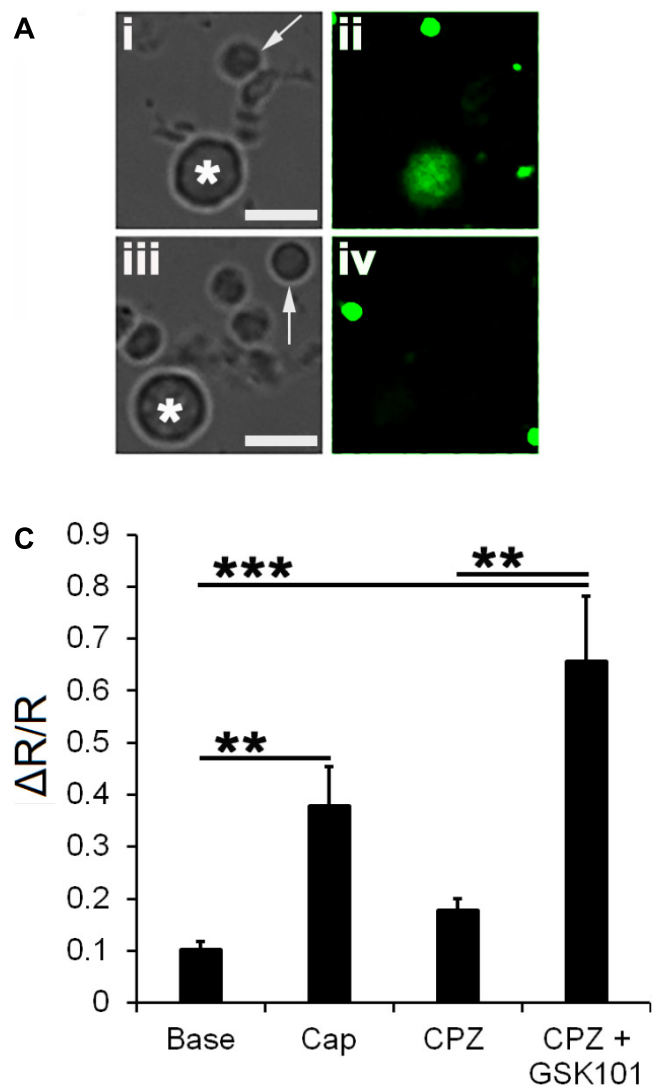

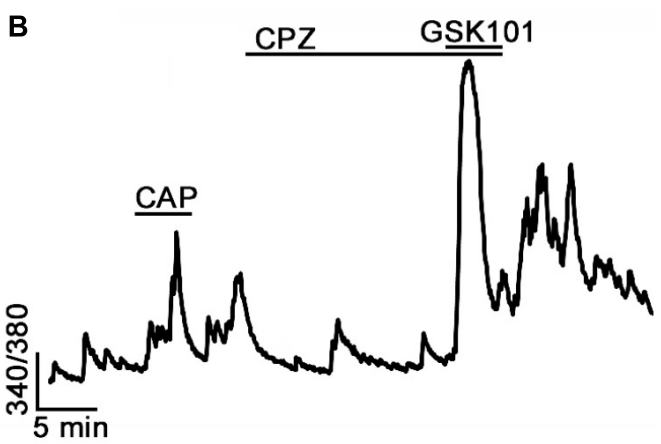

D

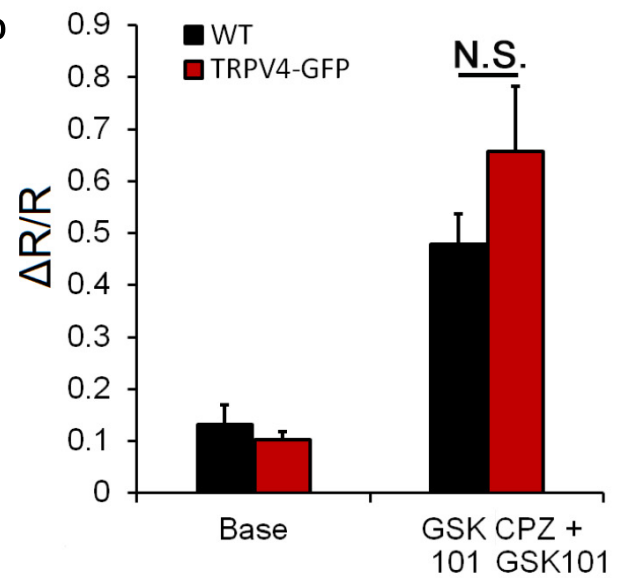

FIGURE 6 | TRPV4 signaling does not require TRPV1. (A) Cells dissociated from transgenic TRPV4GFP retinas (i,ii) and control retinas (iii,iv) show reporter expression in large-diameter neurons (asterisk) but not rod somata (arrow). (B) Representative trace from a TRPV4GFP+ RGC shows a potential response to CAP superimposed on spontaneous background $\mathrm{Ca}^{2+}$ transients. The TRPV1 antagonist CPZ (10 $\left.\mu \mathrm{M}\right)$ did not affect the $\left[\mathrm{Ca}^{2+}\right]_{i}$ baseline or inhibit GSK101-evoked $\left[\mathrm{Ca}^{2+}\right]_{i}$ elevations. (C) Averaged data for CAP and CPZ responses in TRPV4GFP+ RGCs $(n=12)$. (D) CPZ had no effect on the amplitude of GSK101-evoked [Ca $\left.{ }^{2+}\right]_{\mathrm{i}}$ signals $(n=12)$. Scale bar $=10 \mu \mathrm{m}$. N.S., $P<0.05,{ }^{* *} P \leq 0.01,{ }^{* * *} P \leq 0.001$.

suggests that tonic and/or activity dependent release of endocannabinoids might be important for processing of visual signals. Endocannabinoids regulate TRPV1 directly and through CB1R-dependent intracellular messengers (Zygmunt et al., 1999) but were also suggested to influence TRPV4 activation (Watanabe et al., 2003; Ho et al., 2015). Exposure to the endogenous agonist of $\mathrm{CB} 1$ receptor 2-AG suppresses TRPV1 channels in mouse RGC (Jo et al., 2017). To establish whether 2-AG has comparable effects on RGC TRPV4 activation we recorded calcium signals from TRPV4 ${ }^{\mathrm{eGFP}}$ (Figures 7A,B), as well as wild type (black traces, Figures $7 \mathrm{C}-\mathrm{E}$ ) and TRPV1 ${ }^{-/-}$RGCs (orange traces, Figures 7C-E) in the presence or absence of 2AG. Figures $\mathbf{7 B}, \mathbf{C}$ show that 2-AG $(1 \mu \mathrm{M})$ does not affect the $\left[\mathrm{Ca}^{2+}\right]_{\mathrm{RGC}}$ baseline and GSK101-evoked $\left[\mathrm{Ca}^{2+}\right]_{\mathrm{i}}$ signals in both $\mathrm{TRPV}^{+}(0.63 \pm 0.12 ; n=10)$ and TRPV 1 -TRPV $4^{+}(0.56 \pm 0.12$; $n=10)$ RGCs. Moreover, in TRPV1 ${ }^{-/-}$RGCs (Figures 7C-E), GSK101-evoked $\left[\mathrm{Ca}^{2+}\right]_{\mathrm{i}}$ signals recorded in cells preincubated with $2-\mathrm{AG}(0.62 \pm 0.05 ; n=24)$ were also indistinguishable from control responses $(0.59 \pm 0.05 ; n=24)$. Consistent with the pharmacological experiments (Figure 6), we found that ablation of TRPV1 has no effect on GSK101-evoked signals ( $n=8$; Figure 7A). These data suggest that, unlike TRPV1 signals,
TRPV4 signaling in the mouse retina will resist endocannabinoid modulation.

\section{DISCUSSION}

This study provides a number of novel observations that are relevant for the understanding of non-canonical sensory transduction in vertebrate vision. First, we quantified the TRPV isoform expression across RGCs. This is important because it identifies potential targets for mechanical and inflammatory stressors that affect specific subpopulations of these projection neurons. Second, we determined the relative abundance and colocalization of the two most extensively studied vanilloid channel isoforms in mouse RGCs. Third, we provide evidence against obligatory functional heteromerization between TRPV1 and TRPV4 channels. Fourth, we show that a proportion of SMI$32^{+} \alpha$ RGCs - cells known to be sensitive to IOP - coexpress TRPV1 and TRPV4 channels. Together, these findings suggest that projection of sensory information to retinorecipient nuclei in the midbrain is differentially distributed across subpopulations of RGCs. 

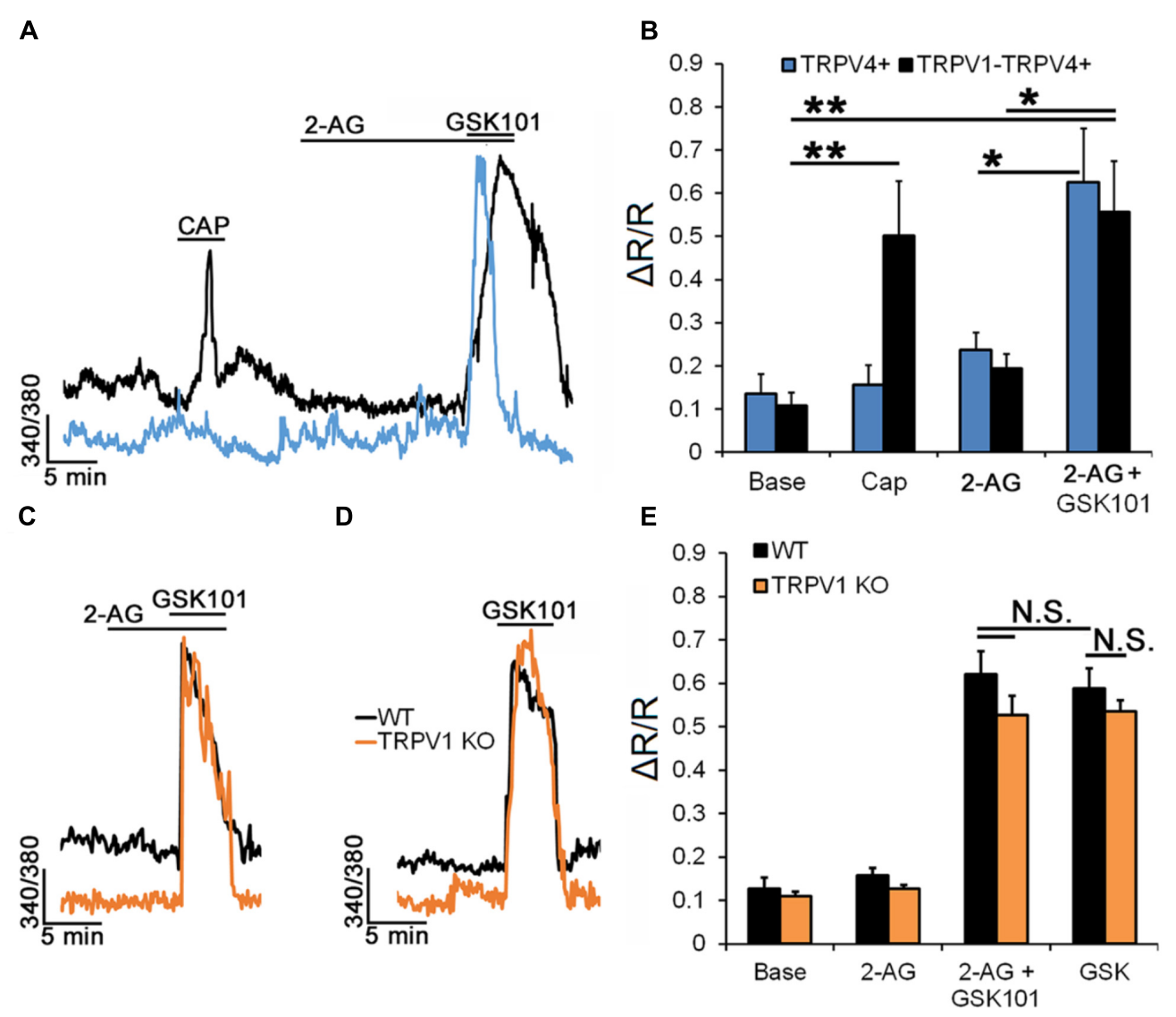

FIGURE 7 | RGC TRPV4 signaling is not modulated by endocannabinoids. Recordings from TRPV4eGFP, wild type (C57), and TRPV1-/- RGCs. (A) Representative traces and (B) cumulative averaged data for CAP and 2-AG responses in TRPV4 ${ }^{+}(n=10)$ and TRPV1-TRPV4 ${ }^{+}(n=10)$ RGCs. (C) Preincubation with 2-AG has no effect on the amplitude of the GSK101-evoked $\left[\mathrm{Ca}^{2+}\right]_{\mathrm{i}}$ response $(n=24)$. (D) Ablation of the Trpv1 gene has no effect on the TRPV4 response $(n=8)$. (E) Cumulative averaged data from WT (black) and TRPV1 (orange) KO RGCs. Neither exposure to 2-AG nor absence of TRPV1 impact GSK101-evoked [Ca $\left.{ }^{2+}\right]_{\mathrm{i}}$ signaling. ${ }^{*} P \leq 0.05,{ }^{* *} P \leq 0.01$.

Transcript analysis in mouse RGCs revealed that the cells express all four non-epithelial vanilloid mRNAs, with Trpv4 by far the most prevalent transcript, followed by Trpv 2 and residual expression of Trpv1 and Trpv3 (Figures 1A,B). Our functional data were broadly reflective of the Trpv transcriptome, with $\sim 50 \%$ RGCs responding to the TRPV4 agonist, $\sim 20 \%$ responded to the TRPV1 agonist, and $\sim 10 \%$ responsive to agonists specific for both channels. A similar expression pattern emerged from immunohistochemical and electrophysiological analyses in the rat DRG, in which $\sim 89 \%$ neurons were shown to express TRPV4, $34 \%$ express TRPV1 channels, and $28 \%$ express projection of both channels (Cao et al., 2009) whereas TRPV1 and TRPV2 (Lewinter et al., 2004) and TRPV1 and TRPM8 displayed little coexpression (Kobayashi et al., 2005). The percentage of TRPV4-ir RGCs exceeds the size of the GSK101-responding pool, presumably because cell dissociation/separation compromises the activation of these stretch-activated channels (e.g., Ryskamp et al., 2011).

TRPV1 and TRPV4 coexpression in mouse RGCs is in accord with quantifications that had been conducted separately for each isoform (Ryskamp et al., 2011; Jo et al., 2017). Previous work localized TRPV4 to RGC somata, and primary dendrites, but there is little information about subcellular TRPV1 expression due to the lack of specificity of TRPV1 antibodies (Gilliam and Wensel, 2011; Molnar et al., 2012). Coexpression of multiple thermoTRPs isoforms in single RGCs suggests that the cells may be capable of parallel transduction of sensory information that includes osmotic gradients, mechanical strain, acidity, and biolipids such as endocannabinoids and polyunsaturated fatty acids (e.g., arachidonic acid and eicosanoids). The possibility that TRPV4 channels mediate the disproportionate sensitivity of certain neurons to mechanical stressors is supported by the observations that (i) TRPV4 activation augments excitability by stimulating TTX-sensitive currents and voltage-operated calcium channels (Li et al., 2011) and increases the firing of substantia nigra (Guatteo et al., 2005), DRG (Cao et al., 2009), hippocampal neurons (Shibasaki et al., 2007), and RGCs (Ryskamp et al., 2011), (ii) TRPV4 mutations underlie debilitating sensory and motor neuropathies (Nilius and Voets, 2013) whereas (iii) $\mathrm{TRPV}^{-/-}$mice exhibit impaired mechanical nociception (Liedtke and Friedman, 2003) and (iv) may be protected from 
mechanical hyperalgesia and glaucomatous neurodegeneration (Alessandri-Haber et al., 2004; Ryskamp et al., 2016). Mice lacking a functional $\operatorname{Trp} v 4$ gene show impaired responses to intense mechanical stimuli but normal responses to low threshold stimulation (Liedtke and Friedman, 2003; Suzuki et al., 2003), suggesting that TRPV4 will preferentially mediate calcium signals in respond to excessive mechanical stress (for example, in hypertensive glaucoma). Consistent with this, elevated calcium levels were reported in glaucomatous RGCs (Niittykoski et al., 2010).

TRPV1 is the most extensively studied retinal vanilloid channel, with reports suggesting pre- and postsynaptic expression across multiple cell types (Yazulla, 2008; Ryskamp et al., 2014b) that include a subpopulation of RGCs (Jo et al., 2017). Although Trpv1 mRNA levels in RGCS were negligible compared to Trpv2 and Trpv4 expression, CAP-responding cells constituted $\sim 20 \%$ of the overall magnetoseparated population. This suggests that low expression of the Trpv1 gene is sufficient to support TRPV1-mediated $\mathrm{Ca}^{2+}$ entry in a substantial mouse RGC cohort. Our findings in the retina mirror previous studies the brain, which was reported to show low Trpv1 expression (Cavanaugh et al., 2011) even though neurons across multiple brain regions respond to CAP with TRPV1-dependent modulation of synaptic plasticity and vesicle release (Gibson et al., 2008; Wu et al., 2014; Fenwick et al., 2017). While physiological functions of retinal TRPV1 have not been clearly defined, its localization to $\alpha$ RGCs, which respond to modest IOP elevations with dendritic and synaptic remodeling (Ou et al., 2016) potentially links pressure-dependent RGC excitability (Weitlauf et al., 2014) and apoptosis (Sappington et al., 2009) to the early loss of large-diameter RGCs exposed to glaucomatous stressors such as IOP (Glovinsky et al., 1991). Arguing against a direct TRPV1 role in pressure transduction are the limited expression of the channel in RGCs and the reports that TRPV1 ablation augments RGC injury in a mouse model of ocular hypertension (Ward et al., 2014). There is also conflicting evidence about whether TRPV1 is expressed in retinal glia, as the channel was reported in rabbit but not detected in rat Müller cells (Leonelli et al., 2009; Martínez-García et al., 2013). Our analysis of reporter mice shows that TRPV1 is expressed in a subset of Müller glia but it remains unclear whether this was due to non-uniformity of Trpv1 expression or an artifact resulting from differential expression of the reporter transgene.

This is the first report that a small but significant fraction of RGCs $(\sim 10 \%)$ functionally coexpress TRPV1 and TRPV4 isoforms. Interestingly, this cohort included cells that were immunopositive for SMI-32, a marker of $\alpha$ RGCs which form four independent mosaics within the IPL-RGCL (Krieger et al., 2017), include M4 ipRGCs (Schmidt et al., 2014), and constitute one of the fastest pathways for retina-brain information transfer. Whether native TRPV1 and TRPV4 channels are capable of heteromultimerization has been controversial given that subunit interactions predicted by FRET studies (Cheng et al., 2007) and co-immunoprecipitation (Sappington et al., 2015) have not been not substantiated by investigations of TRPV1-4 subunit expression in heterologously expressing cells (Hellwig et al., 2005). TRPV4 $4^{-/-}$mice exhibit impaired mechanical nociception but show conserved TRPV1-mediated responses to noxious heat (Liedtke and Friedman, 2003; Suzuki et al., 2003). We expand on these studies to show that heteromerization is not obligatory for the activation of native neuronal TRPV1 or TRPV4 channels as indicated the observation that neither activation nor inhibition of TRPV1 affect the amplitude and kinetics of GSK101-evoked calcium responses. Vice versa, pretreatment with TRPV4 agonists/antagonists had no effect on the cells' responsiveness to CAP. We also found that (i) desensitization of one isoform has little effect on the agonistevoked responsiveness of the other and (ii) CB1 receptor activation which inhibits TRPV1 channels (Jo et al., 2017) has no effect on TRPV4-mediated signals in TRPV1-expressing RGCs; this finding mirrors the analyses in DRG neurons which showed that native TRPV1 and TRPV4 currents can be explained by single channel properties of each channel (Premkumar et al., 2002; Kim et al., 2016). It is possible that interactions between the two channels will emerge under pathological circumstances, as either channel can contribute to mechanical hyperalgesia (Vennekens et al., 2008; Huynh et al., 2014) and both were linked to optic neuropathy (Ryskamp et al., 2011; Weitlauf et al., 2014). Indeed, TRPV1 activation that is not harmful in healthy tissue can be pathological during mechanical hyperalgesia and facilitated by pro-inflammatory molecules that have been implicated in glaucoma such as ATP, prostaglandins, and arachidonic acid metabolites (Nilius and Szallasi, 2014). We hypothesize that TRPV1/4 sensitization ("allodynia") amplifies pressure-induced neuronal damage through eicosanoid products of CYP450, which activate TRPV4 $\left(5^{\prime} 6^{\prime}\right.$-EET, $11^{\prime}, 12^{\prime}$-EET) and TRPV1 (12-(S)-HETE, 20-HETE) (Watanabe et al., 2003; Wen et al., 2012; Ryskamp et al., 2014b) or N-arachidonoyl taurine which activates both channels (Bradshaw et al., 2013). TRPV1/4dependent mechanical allodynia is a characteristic feature of neurogenic inflammatory and neuropathic pain paradigms in sensory neurons (Alessandri-Haber et al., 2004; Amadesi et al., 2006; Grant et al., 2007). Importantly, hyperalgesia-associated properties of thermoTRPs channels would also augment the susceptibility of retinal neurons and glia to glaucomatous injury (Križaj, 2016). Among inflammatory agents that sensitize TRPV1 and TRPV4 are ATP, bradykinin, prostaglandin E2, and PAR2 agonists which have been linked to cytotoxicity and neurodegeneration (Grant et al., 2007; Nilius and Szallasi, 2014; Lu et al., 2015). However, certain messenger molecules may preferentially stimulate one isoform over the other. For example, TRPV4 signaling in RGCs is unaffected by the long-chain unsaturated acyl-amide 2-AG that potently modulates TRPV1 activation (Bradshaw et al., 2013; Ryskamp et al., 2014b; Jo et al., 2017).

Collectively, these findings extend our understanding of how non-canonical sensory stimuli are transduced in mammalian RGCs. We know that the devastating effects of pressure, strain, swelling, ocular trauma and inflammatory inputs on vision tend to be associated with early effects of mechanical stress on the viability and function of RGCs (Križaj, 2016). It remains to be seen whether synergistic activation of TRPV1 and 4 under pathological conditions unlocks novel models of sensory 
transduction, as observed for somatosensory afferents, in which combined expression of TRPV1, TRPM3, and TRPA1 is required for the transduction of noxious heat (Vandewauw et al., 2018). A non-mutually exclusive possibility is that the two vanilloid isoforms impart complementary sensory information that could be important for signaling in specific RGC classes such as $\alpha$ RGCs. Because mouse RGC subpopulations tend to be conserved in primates (Chalupa and Williams, 2008), our findings might extend across phylogenetic domains.

\section{AUTHOR CONTRIBUTIONS}

ML and DK conceived the project. JB, DY, AJ, and ML performed the experiments. $\mathrm{HH}$ contributed transgenic mice. ML and DK analyzed the data and wrote the paper.

\section{REFERENCES}

Alessandri-Haber, N., Dina, O. A., Yeh, J. J., Parada, C. A., Reichling, D. B., and Levine, J. D. (2004). Transient receptor potential vanilloid 4 is essential in chemotherapy-induced neuropathic pain in the rat. J. Neurosci. 24, 4444-4452. doi: 10.1523/JNEUROSCI.0242-04.2004

Amadesi, S., Cottrell, G. S., Divino, L., Chapman, K., Grady, E. F., Bautista, F., et al. (2006). Protease-activated receptor 2 sensitizes TRPV1 by protein kinase Cepsilon- and A-dependent mechanisms in rats and mice. J. Physiol. 575, 555-571. doi: 10.1113/jphysiol.2006.111534

Baden, T., Berens, P., Franke, K., Román Rosón, M., Bethge, M., and Euler, T. (2016). The functional diversity of retinal ganglion cells in the mouse. Nature 529, 345-350. doi: 10.1038/nature16468

Bradshaw, H. B., Raboune, S., and Hollis, J. L. (2013). Opportunistic activation of TRP receptors by endogenous lipids: exploiting lipidomics to. Understand TRP receptor cellular communication. Life Sci. 92, 404-409. doi: 10.1016/j.lfs.2012. 11.008

Cao, D. S., Yu, S. Q., and Premkumar, L. S. (2009). Modulation of transient receptor potential Vanilloid 4-mediated membrane currents and synaptic transmission by protein kinase C. Mol. Pain 5:5. doi: 10.1186/1744-8069-5-5

Caterina, M. J., Schumacher, M. A., Tominaga, M., Rosen, T. A., Levine, J. D., and Julius, D. (1997). The capsaicin receptor: a heat-activated ion channel in the pain pathway. Nature 389, 816-824. doi: 10.1038/39807

Cavanaugh, D. J., Chesler, A. T., Jackson, A. C., Sigal, Y. M., Yamanaka, H., Grant, R., et al. (2011). Trpv1 reporter mice reveal highly restricted brain distribution and functional expression in arteriolar smooth muscle cells. J. Neurosci. 31, 5067-5077. doi: 10.1523/JNEUROSCI.6451-10.2011

Chalupa, L. M., and Williams, R. W. (2008). Eye, Retina, and Visual System of the Mouse. Cambridge, MA: MIT Press.

Cheng, W., Yang, F., Takanishi, C. L., and Zheng, J. (2007). Thermosensitive TRPV channel subunits coassemble into heteromeric channels with intermediate conductance and gating properties. J. Gen. Physiol. 129, 191-207. doi: 10.1085/ jgp. 200709731

Clapham, D. E. (2003). TRP channels as cellular sensors. Nature 426, 517-524. doi: 10.1038/nature02196

Coombs, J., van der List, D., Wang, G. Y., and Chalupa, L. M. (2006). Morphological properties of mouse retinal ganglion cells. Neuroscience 140, 123-136. doi: 10.1016/j.neuroscience.2006.02.079

Della Santina, L., Inman, D. M., Lupien, C. B., Horner, P. J., and Wong, R. O. (2013). Differential progression of structural and functional alterations in distinct retinal ganglion cell types in a mouse model of glaucoma. J. Neurosci. 33, 17444-17457. doi: 10.1523/JNEUROSCI.5461-12. 2013

Duan, X., Qiao, M., Bei, F., Kim, I. J., He, Z., and Sanes, J. R. (2015). Subtypespecific regeneration of retinal ganglion cells following axotomy: effects of osteopontin and mTOR signaling. Neuron 85, 1244-1256. doi: 10.1016/j. neuron.2015.02.017

\section{FUNDING}

This work was supported by the National Institutes of Health (EY022076, EY027920, T32EY024234, and P30EY014800), Willard L. Eccles Foundation, Glaucoma Research Foundation (DK), the University of Utah Undergraduate Research Opportunity Program (DY and AJ), and unrestricted support from Research to Prevent Blindness to the Moran Eye Institute at the University of Utah.

\section{ACKNOWLEDGMENTS}

We thank Dr. Maureen McCall (University of Louisville) for the transgenic TRPV1 retinas and Dr. Wolfgang Liedtke (Duke University) for TRPV4 ${ }^{-/-}$mice.

Echaniz-Laguna, A., Dubourg, O., Carlier, P., Carlier, R. Y., Sabouraud, P., Péréon, Y., et al. (2014). Phenotypic spectrum and incidence of TRPV4 mutations in patients with inherited axonal neuropathy. Neurology 82, 19191926. doi: 10.1212/WNL.0000000000000450

Fenwick, A. J., Fowler, D. K., Wu, S. W., Shaffer, F. J., Lindberg, J. E. M., Kinch, D. C., et al. (2017). Direct anandamide activation of TRPV1 produces divergent calcium and current responses. Front. Mol. Neurosci. 10:200. doi: 10.3389/ fnmol.2017.00200

Gibson, H. E., Edwards, J. G., Page, R. S., Van Hook, M. J., and Kauer, J. A. (2008). TRPV1 channels mediate long-term depression at synapses on hippocampal interneurons. Neuron 57, 746-759. doi: 10.1016/j.neuron.2007.12.027

Gilliam, J. C., and Wensel, T. G. (2011). TRP channel gene expression in the mouse retina. Vision Res. 51, 2440-2452. doi: 10.1016/j.visres.2011.10.009

Glovinsky, Y., Quigley, H. A., and Dunkelberger, G. R. (1991). Retinal ganglion cell loss is size dependent in experimental glaucoma. Invest. Ophthalmol. Vis. Sci. $32,484-491$.

Grant, A. D., Cottrell, G. S., Amadesi, S., Trevisani, M., Nicoletti, P., Materazzi, S., et al. (2007). Protease-activated receptor 2 sensitizes the transient receptor potential vanilloid 4 ion channel to cause mechanical hyperalgesia in mice. J. Physiol. 578, 715-733. doi: 10.1113/jphysiol.2006.121111

Gu, Q. D., Moss, C. R. II, Kettelhut, K. L., Gilbert, C. A., and Hu, H. (2016). Activation of TRPV4 regulates respiration through indirect activation of bronchopulmonary sensory neurons. Front. Physiol. 7:65. doi: 10.3389/fphys. 2016.00065

Guatteo, E., Chung, K. K., Bowala, T. K., Bernardi, G., Mercuri, N. B., and Lipski, J. (2005). Temperature sensitivity of dopaminergic neurons of the substantia nigra pars compacta: involvement of transient receptor potential channels. J. Neurophysiol. 94, 3069-3080. doi: 10.1152/jn.00066.2005

Hellwig, N., Albrecht, N., Harteneck, C., Schultz, G., and Schaefer, M. (2005). Homo- and heteromeric assembly of TRPV channel subunits. J. Cell Sci. 118, 917-928. doi: 10.1242/jcs.01675

Ho, W. S., Zheng, X., and Zhang, D. X. (2015). Role of endothelial TRPV4 channels in vascular actions of the endocannabinoid, 2-arachidonoylglycerol. Br. J. Pharmacol. 172, 5251-5264. doi: 10.1111/bph.13312

Huynh, K. W., Cohen, M. R., Chakrapani, S., Holdaway, H. A., Stewart, P. L., and Moiseenkova-Bell, V. Y. (2014). Structural insight into the assembly of TRPV channels. Structure 22, 260-268. doi: 10.1016/j.str.2013.11.008

Jo, A., Ryskamp, D., Phuong, T., Verkman, A., Yarishkin, O., MacAulay, N., et al. (2015). TRPV4 and AQP4 channels synergistically regulate cells volume and calcium homeostasis in retinal Müller glia. J. Neurosci. 35, 13525-13537. doi: 10.1523/JNEUROSCI.1987-15.2015

Jo, A. O., Lakk, M., Frye, A. M., Phuong, T. T., Redmon, S. N., Roberts, R., et al. (2016). Differential volume regulation and calcium signaling in two ciliary body cell types is subserved by TRPV4 channels. Proc. Natl. Acad. Sci. U.S.A. 113, 3885-3890. doi: 10.1073/pnas.1515895113

Jo, A. O., Noel, J. M., Lakk, M., Yarishkin, O., Ryskamp, D. A., Shibasaki, K., et al. (2017). Mouse retinal ganglion cell signalling is dynamically modulated 
through parallel anterograde activation of cannabinoid and vanilloid pathways. J. Physiol. 595, 6499-6516. doi: 10.1113/JP274562

Kim, S., Barry, D. M., Liu, X. Y., Yin, S., Munanairi, A., Meng, Q. T., et al. (2016). Facilitation of TRPV4 by TRPV1 is required for itch transmission in some sensory neuron populations. Sci. Signal. 9:ra71. doi: 10.1126/scisignal.aaf1047

Kobayashi, K., Fukuoka, T., Obata, K., Yamanaka, H., Dai, Y., Tokunaga, A., et al. (2005). Distinct expression of TRPM8, TRPA1, and TRPV1 mRNAs in rat primary afferent neurons with adelta/c-fibers and colocalization with trk receptors. J. Comp. Neurol. 493, 596-606. doi: 10.1002/cne.20794

Krieger, B., Qiao, M., Rousso, D. L., Sanes, J. R., and Meister, M. (2017). Four alpha ganglion cell types in mouse retina: function, structure, and molecular signatures. PLoS One 12:e0180091. doi: 10.1371/journal.pone.0180091

Križaj, D. (2016). Polymodal sensory integration in retinal ganglion cells. Adv. Exp. Med. Biol. 854, 693-698. doi: 10.1007/978-3-319-17121-0_92

Križaj, D., Ryskamp, D. A., Tian, N., Tezel, G., Mitchell, C. H., Slepak, V. Z., et al. (2014). From mechanosensitivity to inflammatory responses: new players in the pathology of glaucoma. Curr. Eye Res. 39, 105-119. doi: 10.3109/02713683.2013. 836541

Lakk, M., Yarishkin, O., Baumann, J. M., Iuso, A., and Križaj, D. (2017). Cholesterol regulates polymodal sensory transduction in Müller glia. Glia 65, 2038-2050. doi: $10.1002 /$ glia. 23213

Leonelli, M., Martins, D. O., Kihara, A. H., and Britto, L. R. (2009). Ontogenetic expression of the vanilloid receptors TRPV1 and TRPV2 in the rat retina. Int. J. Dev. Neurosci. 27, 709-718. doi: 10.1016/j.ijdevneu.2009.07.003

Lettvin, J. Y., Maturana, H. R., McCulloch, W. S., and Pitts, W. H. (1959). What the frog's eye tells the frog's brain. Proc. IRE 47, 1940-1951. doi: 10.1109/JRPROC. 1959.287207

Lewinter, R. D., Skinner, K., Julius, D., and Basbaum, A. I. (2004). Immunoreactive TRPV-2 (VRL-1), a capsaicin receptor homolog, in the spinal cord of the rat. J. Comp. Neurol. 470, 400-408. doi: 10.1002/cne.20024

Li, L., Liu, C., Chen, L., and Chen, L. (2011). Hypotonicity modulates tetrodotoxinsensitive sodium current in trigeminal ganglion neurons. Mol. Pain 7:27. doi: $10.1186 / 1744-8069-7-27$

Liedtke, W., and Friedman, J. M. (2003). Abnormal osmotic regulation in Trpv4/- mice. Proc. Natl. Acad. Sci. U.S.A. 100, 13698-13703. doi: 10.1073/pnas. 1735416100

Lu, W., Hu, H., Sévigny, J., Gabelt, B. T., Kaufman, P. L., Johnson, E. C., et al. (2015). Rat, mouse, and primate models of chronic glaucoma show sustained elevation of extracellular ATP and altered purinergic signaling in the posterior eye. Invest. Ophthalmol. Vis. Sci. 56, 3075-3083. doi: 10.1167/iovs.14-15891

Ma, Y., Zhang, P., Li, J., Lu, J., Ge, J., Zhao, Z., et al. (2015). Epoxyeicosatrienoic acids act through TRPV4-TRPC1-KCa1.1 complex to induce smooth muscle membrane hyperpolarization and relaxation in human internal mammary arteries. Biochim. Biophys. Acta 1852, 552-559. doi: 10.1016/j.bbadis.2014.12. 010

Madison, L., Zwingman, T. A., Sunkin, S. M., Oh, S. W., Zariwala, H. A., Gu, H., et al. (2010). A robust and high-throughput Cre reporting and characterization system for the whole mouse brain. Nat. Neurosci. 13, 133-140. doi: 10.1038/nn. 2467

Martínez-García, M. C., Martínez, T., Pañeda, C., Gallego, P., Jimenez, A. I., and Merayo, J. (2013). Differential expression and localization of transient receptor potential vanilloid 1 in rabbit and human eyes. Histol. Histopathol. 28, 1507-1516. doi: 10.14670/HH-28.1507

Martins, D., Tavares, I., and Morgado, C. (2014). "Hotheaded": the role OF TRPV1 in brain functions. Neuropharmacology 85, 151-157. doi: 10.1016/j. neuropharm.2014.05.034

Middleton, T. P., and Protti, D. A. (2011). Cannabinoids modulate spontaneous synaptic activity in retinal ganglion cells. Vis. Neurosci. 28, 393-402. doi: 10. 1017/S0952523811000198

Mishra, S. K., and Hoon, M. A. (2010). Ablation of TrpV1 neurons reveals their selective role in thermal pain sensation. Mol. Cell. Neurosci. 43, 157-163. doi: 10.1016/j.mcn.2009.10.006

Molnar, T., Barabas, P., Birnbaumer, L., Punzo, C., Kefalov, V., and Križaj, D. (2012). Store-operated channels regulate intracellular calcium in mammalian rods. J. Physiol. 590, 3465-3481. doi: 10.1113/jphysiol.2012.234641

Molnar, T., Yarishkin, O., Iuso, A., Barabas, P., Jones, B., Marc, R. E., et al. (2016). Store-operated calcium entry in Müller glia is controlled by synergistic activation of TRPC and Orai channels. J. Neurosci. 36, 3184-3198. doi: 10.1523/ JNEUROSCI.4069-15.2016

Morin, L. P., and Studholme, K. M. (2014). Retinofugal projections in the mouse. J. Comp. Neurol. 522, 3733-3753. doi: 10.1002/cne.23635

Muller, L. P. D., Sargoy, A., Rodriguez, A. R., and Brecha, N. C. (2014). Melanopsin ganglion cells are the most resistant retinal ganglion cell type to axonal injury in the rat retina. PLoS One 9:e93274. doi: 10.1371/journal.pone.0093274

Niittykoski, M., Kalesnykas, G., Larsson, K. P., Kaarniranta, K., Akerman, K. E., and Uusitalo, H. (2010). Altered calcium signaling in an experimental model of glaucoma. Invest. Ophthalmol. Vis. Sci. 51, 6387-6393. doi: 10.1167/iovs.093816

Nilius, B., and Szallasi, A. (2014). Transient receptor potential channels as drug targets: from the science of basic research to the art of medicine. Pharmacol. Rev. 66, 676-814. doi: 10.1124/pr.113.008268

Nilius, B., and Voets, T. (2013). The puzzle of TRPV4 channelopathies. EMBO Rep. 14, 152-163. doi: 10.1038/embor.2012.219

Ou, Y., Jo, R. E., Ullian, E. M., Wong, R. O., and Della Santina, L. (2016). Selective vulnerability of specific retinal ganglion cell types and synapses after transient ocular hypertension. J. Neurosci. 36, 9240-9252. doi: 10.1523/JNEUROSCI. 0940-16.2016

Phuong, T. T. T., Redmon, S. N., Yarishkin, O., Winter, J. M., Li, D. Y., and Križaj, D. (2017). Calcium influx through TRPV4 channels modulates the adherens contacts between retinal microvascular endothelial cells. J. Physiol. 595, 6869-6885. doi: 10.1113/JP275052

Premkumar, L. S., Agarwal, S., and Steffen, D. (2002). Single-channel properties of native and cloned rat vanilloid receptors. J. Physiol. 545, 107-117. doi: 10.1113/ jphysiol.2002.016352

Ramírez-Barrantes, R., Cordova, C., Poblete, H., Muñoz, P., Marchant, I., Wianny, F., et al. (2016). Perspectives of TRPV1 function on the neurogenesis and neural plasticity. Neural Plast. 2016:1568145. doi: 10.1155/2016/1568145

Raymond, I. D., Vila, A., Huynh, U. C., and Brecha, N. C. (2008). Cyan fluorescent protein expression in ganglion and amacrine cells in a Thyl-CFP transgenic mouse retina. Mol. Vis. 14, 1559-1574.

Redmon, S. N., Shibasaki, K., and Krizaj, D. (2017). “Transient receptor potential cation channel subfamily V member 4," in Encyclopedia of Signaling Molecules, 2nd Edn, ed. S. Choi (Berlin: Springer Verlag).

Ryskamp, D. A., Frye, A. M., Phuong, T. T. T., Yarishkin, O., Jo, A. O., Xu, Y., et al. (2016). TRPV4 regulates calcium homeostasis, cytoskeletal remodeling, conventional outflow and intraocular pressure in the mammalian eye. Sci. Rep. 6:30583. doi: 10.1038/srep30583

Ryskamp, D. A., Iuso, A., and Križaj, D. (2015). TRPV4 links inflammatory signaling and neuroglial swelling. Channels 9, 70-72. doi: 10.1080/19336950. 2015.1017998

Ryskamp, D. A., Jo, A. O., Frye, A. M., Vazquez-Chona, F., MacAulay, N., Thoreson, W. B., et al. (2014a). Swelling and eicosanoid metabolites differentially gate TRPV4 channels in retinal neurons and glia. J. Neurosci. 34, 15689-15700. doi: 10.1523/JNEUROSCI.2540-14.2014

Ryskamp, D. A., Redmon, S., Jo, A. O., and Križaj, D. (2014b). TRPV1 and endocannabinoids: emerging molecular signals that modulate mammalian vision. Cells 3, 914-938. doi: 10.3390/cells3030914

Ryskamp, D. A., Witkovsky, P., Barabas, P., Huang, W., Koehler, C., Akimov, N. P., et al. (2011). The polymodal ion channel transient receptor potential vanilloid 4 modulates calcium flux, spiking rate, and apoptosis of mouse retinal ganglion cells. J. Neurosci. 31, 7089-7101. doi: 10.1523/JNEUROSCI.0359-11.2011

Sappington, R. M., Sidorova, T., Long, D. J., and Calkins, D. J. (2009). TRPV1: contribution to retinal ganglion cell apoptosis and increased intracellular Ca2 ${ }^{+}$ with exposure to hydrostatic pressure. Invest. Ophthalmol. Vis. Sci. 50, 717-728. doi: 10.1167/iovs.08-2321

Sappington, R. M., Sidorova, T., Ward, N. J., Chakravarthy, R., Ho, K. W., and Calkins, D. J. (2015). Activation of transient receptor potential vanilloid-1 (TRPV1) influences how retinal ganglion cell neurons respond to pressurerelated stress. Channels 9, 102-113. doi: 10.1080/19336950.2015.1009272

Schmidt, T. M., Alam, N. M., Chen, S., Kofuji, P., Li, W., Prusky, G. T., et al. (2014). A role for melanopsin in alpha retinal ganglion cells and contrast detection. Neuron 82, 781-788. doi: 10.1016/j.neuron.2014.03.022

Shibasaki, K., Suzuki, M., Mizuno, A., and Tominaga, M. (2007). Effects of body temperature on neural activity in the hippocampus: regulation of resting 
membrane potentials by transient receptor potential vanilloid 4. J. Neurosci. 27, 1566-1575. doi: 10.1523/JNEUROSCI.4284-06.2007

Sousa-Valente, J., Andreou, A. P., Urban, L., and Nagy, I. (2014). Transient receptor potential ion channels in primary sensory neurons as targets for novel analgesics. Br. J. Pharmacol. 171, 2508-2527. doi: 10.1111/bph.12532

Stewart, A. P., Smith, G. D., Sandford, R. N., and Edwardson, J. M. (2010). Atomic force microscopy reveals the alternating subunit arrangement of the TRPP2-TRPV4 heterotetramer. Biophys. J. 99, 790-797. doi: 10.1016/j.bpj.2010. 05.012

Sudbury, J. R., Ciura, S., Sharif-Naeini, R., and Bourque, C. W. (2010). Osmotic and thermal control of magnocellular neurosecretory neurons-role of an N-terminal variant of TRPV1. Eur. J. Neurosci. 32, 2022-2030. doi: 10.1111/j.1460-9568. 2010.07512.x

Suzuki, M., Mizuno, A., Kodaira, K., and Imai, M. (2003). Impaired pressure sensation in mice lacking TRPV4. J. Biol. Chem. 278, 22664-22668. doi: 10. 1074/jbc.M302561200

Taylor, L., Arnér, K., and Ghosh, F. (2017). Specific inhibition of TRPV4 enhances retinal ganglion cell survival in adult porcine retinal explants. Exp. Eye Res. 154, 10-21. doi: 10.1016/j.exer.2016.11.002

Teichert, R. W., Memon, T., Aman, J. W., and Olivera, B. M. (2014). Using constellation pharmacology to define comprehensively a somatosensory neuronal subclass. Proc. Natl. Acad. Sci. U.S.A. 111, 2319-2324. doi: 10.1073/ pnas. 1324019111

Tominaga, M., Caterina, M. J., Malmberg, A. B., Rosen, T. A., Gilbert, H., Skinner, K., et al. (1998). The cloned capsaicin receptor integrates multiple painproducing stimuli. Neuron 21, 531-543. doi: 10.1016/S0896-6273(00)80564-4

Vandewauw, I., De Clercq, K., Mulier, M., Held, K., Pinto, S., Van Ranst, N., et al. (2018). A TRP channel trio mediates acute noxious heat sensing. Nature 555, 662-666. doi: 10.1038/nature26137

Vennekens, R., Owsianik, G., and Nilius, B. (2008). Vanilloid transient receptor potential cation channels: an overview. Curr. Pharm. Des. 14, 18-31. doi: 10. 2174/138161208783330763

Ward, N. J., Ho, K. W., Lambert, W. S., Weitlauf, C., and Calkins, D. J. (2014). Absence of transient receptor potential vanilloid-1 accelerates stress-induced axonopathy in the optic projection. J. Neurosci. 34, 3161-3170. doi: 10.1523/ JNEUROSCI.4089-13.2014

Watanabe, H., Vriens, J., Prenen, J., Droogmans, G., Voets, T., and Nilius, B. (2003). Anandamide and arachidonic acid use epoxyeicosatrienoic acids to activate TRPV4 channels. Nature 424, 434-438. doi: 10.1038/nature01807
Weitlauf, C., Ward, N. J., Lambert, W. S., Sidorova, T. N., Ho, K. W., Sappington, R. M., et al. (2014). Short-term increases in transient receptor potential vanilloid-1 mediate stress-induced enhancement of neuronal excitation. J. Neurosci. 34, 15369-15381. doi: 10.1523/JNEUROSCI.3424-14.2014

Wen, H., Ostman, J., Bubb, K. J., Panayiotou, C., Priestley, J. V., Baker, M. D., et al. (2012). 20-Hydroxyeicosatetraenoic acid (20-HETE) is a novel activator of transient receptor potential vanilloid 1 (TRPV1) channel. J. Biol. Chem. 287, 13868-13876. doi: 10.1074/jbc.M111.334896

White, J. P., Cibelli, M., Urban, L., Nilius, B., McGeown, J. G., and Nagy, I. (2016). TRPV4: molecular conductor of a diverse orchestra. Physiol. Rev. 96, 911-973. doi: 10.1152/physrev.00016.2015

Wu, T. T., Peters, A. A., Tan, P. T., Roberts-Thomson, S. J., and Monteith, G. R. (2014). Consequences of activating the calcium-permeable ion channel TRPV1 in breast cancer cells with regulated TRPV1 expression. Cell Calcium 56, 59-67. doi: 10.1016/j.ceca.2014.04.006

Yarishkin, O., Phuong, T. T. T., Lakk, M., and Križaj, D. (2018). TRPV4 does not regulate the distal retinal light response. Adv. Exp. Med. Biol. 1074, 553-560. doi: 10.1007/978-3-319-75402-4_67

Yazulla, S. (2008). Endocannabinoids in the retina: from marijuana to neuroprotection. Prog. Retin. Eye Res. 27, 501-526. doi: 10.1016/j.preteyeres. 2008.07.002

Zeng, H., and Sanes, J. R. (2017). Neuronal cell-type classification: challenges, opportunities and the path forward. Nat. Rev. Neurosci. 18, 530-546. doi: 10. 1038/nrn.2017.85

Zygmunt, P. M., Petersson, J., Andersson, D. A., Chuang, H., Sørgård, M., Di Marzo, V., et al. (1999). Vanilloid receptors on sensory nerves mediate the vasodilator action of anandamide. Nature 400, 452-457. doi: 10.1038/22761

Conflict of Interest Statement: The authors declare that the research was conducted in the absence of any commercial or financial relationships that could be construed as a potential conflict of interest.

Copyright (c) 2018 Lakk, Young, Baumann, Jo, Hu and Križaj. This is an open-access article distributed under the terms of the Creative Commons Attribution License (CC BY). The use, distribution or reproduction in other forums is permitted, provided the original author(s) and the copyright owner(s) are credited and that the original publication in this journal is cited, in accordance with accepted academic practice. No use, distribution or reproduction is permitted which does not comply with these terms. 